\title{
O EXAME DE SUFICIÊNCIA NA PERCEPÇÃO DOS ALUNOS DE CIÊNCIAS CONTÁBEIS
}

\section{THE SUFFICIENCY EXAM ON THE PERCEPTION OF ACCOUNTING SCIENCES STUDENTS}

\author{
JOELSON VISCOVINI DA SILVA \\ Universidade do Estado de Mato Grosso. Endereço: Rua Guanandi, 02 | \\ Santos Dumont | 78211-395 | Cáceres/MT | Brasil. \\ (1) http://orcid.org/0000-0002-9753-7896 \\ joelson_viscovini2015@hotmail.com
}

\section{ALMIR RODRIGUES DURIGON}

Universidade do Estado de Mato Grosso. Endereço: Rua Marcílio Dias, 243| São Luiz | 78205-155 | Cáceres/MT | Brasil.

(1) http://orcid.org/0000-0002-3460-2048

ardurigon@edu.unisinos.br

\author{
JULIANA VITÓRIA VIEIRA MATTIELLO DA \\ SILVA \\ Universidade do Estado de Mato Grosso. Endereço: Rua dos pescadores, 06 \\ Cavalhada | 78216-110| Cáceres/MT | Brasil. \\ (D) http://orcid.org/0000-0002-7295-6541 \\ julianamattiello@unemat.br
}

\section{RUBENS DOS SANTOS}

Universidade do Estado de Mato Grosso. Endereço: Rua dos Mutuns, 261| Santa Isabel | CEP 78205-750| Cáceres/MT | Brasil.

(D) http://orcid.org/0000-0003-4608-6279

rubens@unemat.br

\section{RESUMO}

O Exame de Suficiência é definido pelo Conselho Federal de Contabilidade (CFC) como prova de equalização destinada a comprovar a obtenção de conhecimentos médios, consoante aos conteúdos programáticos desenvolvidos nos cursos de bacharelado em Ciências Contábeis. Considerando esse contexto, este artigo objetiva identificar as percepções dos alunos sobre a realização do exame de suficiência. O estudo classifica-se em pesquisa exploratório-descritiva, dispondo de coleta de dados realizada por meio de um questionário aplicado pessoalmente pelos pesquisadores, contando com a participação de 188 alunos de graduação em Ciências Contábeis (cerca de 58,75\% da população), de uma universidade pública do Estado de Mato Grosso, no ano de 2019. Os dados foram tratados com as seguintes técnicas estatísticas: estatística descritiva (média, mediana, frequência, máximo, mínimo e soma) e análise fatorial. Os resultados da pesquisa indicam que a importância e necessidade de aplicação do exame de suficiência para a profissão contábil é considerada a mais valorizada pelos discentes. $\mathrm{Na}$ análise fatorial, ficou evidente que valorização profissional tem maior peso nas percepções dos alunos $(88,15 \%)$, seguido do ambiente acadêmico 
com 6,39\%. Conclui-se que o Exame de Suficiência, na percepção dos alunos, é um instrumento que valoriza a profissão contábil, entretanto é necessário que os docentes discutam mais pontualmente sobre essa temática em sala de aula.

Palavras-chaves: Exame. Suficiência. Percepção. Alunos. Contabilidade.

\begin{abstract}
The Sufficiency Exam is defined by the Federal Accounting Council (CFC) as an equalization test, designed to prove the achievement of average knowledge, according to the syllabus developed in the Bachelor of Science courses in Accounting. Considering this context, this article aims to identify students' perceptions about taking the sufficiency test. The study is classified as an exploratory-descriptive research, with data collection performed by means of a questionnaire applied by the researchers in person, with the participation of 188 undergraduate students in Accounting Sciences (about 58.75\% of the population), from a public university of the State of Mato Grosso, in 2019. Data have been treated with the following statistical techniques: descriptive statistics (mean, median, frequency, maximum, minimum and sum) and factor analysis. The research results indicate that the importance and need to apply the sufficiency test for the accounting profession is considered most valued by the students. In the factor analysis, it became evident that professional valorization has a greater weight in the students' perceptions (88.15\%), followed by the academic environment with $6.39 \%$. We come to the conclusion that the Sufficiency Exam, at a students' perception, is an instrument that values the accounting profession, however it is necessary that teachers discuss this theme more punctually in classroom.
\end{abstract}

Keywords: Exam. Sufficiency. Perception. Students. Accounting.

\title{
1 INTRODUÇÃO
}

No Brasil, para atuar na profissão contábil, o bacharel deve submeter-se ao exame de licenciamento profissional, conhecido como Exame de Suficiência do Conselho Federal de Contabilidade (CFC), que se constitui como uma condição necessária para o exercício da profissão. A sua obrigatoriedade foi instituída em 1999, através da Resolução CFC n. 853 (CFC, 1999), sendo suspenso em 2005, por intermédio do Ministério Público, alegando que esta exigência não possuía respaldo legal. Com a suspenção os bacharéis voltaram a solicitar seu registro sem a necessidade da submissão ao exame. Somente em 2010 o CFC conseguiu o retorno do licenciamento profissional por meio da Lei n. 12.429 (2010), tornando a aprovação do bacharel em Ciências Contábeis elemento obrigatório para a obtenção de registro e, assim, poder exercer a profissão de contador.

Na literatura sobre exame de licenciamento ocupacional encontram-se duas visões oposta sobre essa temática. A primeira é que os conselhos que representam as profissões defendem que o objetivo do exame é proteger a sociedade de maus profissionais (Pagliero, 2011). A segunda pressupõe que os órgãos que representam a profissão atuam em seu próprio interesse (Stigler, 1971; Becker, 1986; Peltzman, 1984, Graddy, 1991), como criar reservas de mercado, favorecendo aos que já estão atuando na profissão (Thornton, Timmons \& Deantonio, 2017).

Outra questão que se coloca em discussão quando o exame de suficiência é abordado é referente ao índice de aprovação dos alunos. Nessa direção destaca-se estudos que apontam para o decréscimo significativo nas aprovações do exame de suficiência explorando as variáveis que exercem influência no resultado deste. Segundo Sprenger, Kronbauer, Silvestre, Azevedo e Alves (2018), ao abordar os fatores que explicam o índice médio de aprovação do exame de suficiência por unidade federativa, afirma que o índice de aprovação nacional é baixo, correspondendo à $35 \%$. Para Barroso (2018), o resultado positivo dos egressos no instrumento avaliativo profissional tem relação direta com os atributos que as instituições apresentam, tais como bom desempenho no 
Exame Nacional de Desempenho dos Estudantes, melhores avaliações no Índice Geral de Cursos (IGC), pertencimento a uma universidade pública localizada nos grandes centros brasileiro, ser citado no Ranking Universitário da Folha e possuir programas de pós-graduação em Contabilidade. Essas características apresentam significância estatística e coeficiente estimado positivo o que explica, de certa forma, o desempenho das Instituições de Ensino Superior (IES) no exame do CFC.

Nessa direção, esta investigação traz algumas ponderações sobre o exame de suficiência na percepção dos alunos de Ciências Contábeis norteadas pelo seguinte questionamento: qual a percepção dos alunos sobre a realização do exame de suficiência? Objetiva-se com essa pesquisa identificar as percepções dos alunos sobre a realização do exame de suficiência. Análises cujo objetivo é apreciar a percepção são significativas, não para expressar a opinião certa ou errada, mas para compreender o que determinados grupos pensam sobre o assunto investigado (Rabuske, 1995).

Justifica-se o presente estudo pela contribuição com informações à profissão contábil sobre os atributos que são valorizados pelos alunos e, dessa forma, ao conhecer tais pontos, provocar reflexões em prol do aperfeiçoamento do referido exame bem como possibilitar discussões no âmbito estudantil. Este estudo se diferencia dos demais pela forma como explora a concepção dos discentes sobre tal instrumento, pois, ao identificar as características mais valorizadas pelos alunos, é possível definir os principais aspectos a serem trabalhados pelo CFC e docentes, concorrendo para as questões mais consideradas pelos alunos.

Além disso, a pesquisa surge em complemento à diversas outras realizadas sobre o tema, destacando-se Peterson e Reider (2002), Santos e Andrade (2016), Galvão (2016), Miranda, Araújo e Matos Miranda (2017), Sprenger et al. (2018), Morikawa (2018), Barroso (2018) e, Souza, Barreto e Gomes Filho (2019).

Após explanação dessas considerações iniciais e com intuito de atingir o objetivo proposto, o presente artigo, na sequência, apresenta o referencial teórico, sucedido pela apresentação da metodologia utilizada, a análise dos dados e as considerações finais e, por último referências.

\section{REFERENCIAL TEÓRICO}

\subsection{Exame de licenciamento profissional}

Exames de licenciamento são instrumentos utilizados pelos conselhos profissionais para conceder autorização de exercício da profissão e são comuns entre médicos, advogados e professores (Morikawa, 2018). Morikawa (2018) afirma que o principal objetivo do licenciamento profissional é proteger os consumidores da assimetria de informação inerentes às profissões, pois no setor de serviço, no qual a assimetria de informação entre provedores de serviços e usuários é séria, muitas ocupações são reguladas pelo sistema de licenciamento. A assimetria de informação se dá quando o profissional conhece as suas aptidões, mas o consumidor não tem conhecimento sobre a qualidade do serviço (Cox \& Foster, 1990).

Nesse sentido, no Brasil, segundo o CFC (2015), o objetivo do exame é comprovar a obtenção de conhecimentos médios, consoante aos conteúdos programáticos desenvolvidos no curso de bacharelado em Ciências Contábeis. Para Madeira, Mendonça e Abreu (2003) o exame de licenciamento, além de fornecer habilitação profissional, serve também como instrumento de apoio aos cursos de graduação em Ciências Contábeis em seu processo de avaliação e acompanhamento, pois o acesso às provas permite verificar os conteúdos exigidos e compará-los com aqueles ministrados em sala de aula.

Os modelos construídos por Akerlof (1970) e Leland (1979) retratam os exames de suficiência como uma barreira importante e necessária à entrada e, principalmente, como sinal de qualidade, uma vez que a aprovação no exame de licenciamento profissional contábil é condição necessária para se tornar um contador, mas não o suficiente, devido a outros requisitos (Grant, Ciccotello \& Dickie, 2002). 
Conforme Thornton et al. (2017), os exames de licenciamento protegem o interesse da sociedade de profissionais incompetentes ou desrespeitosos, além de garantir um nível elevado de qualidade do serviço. Nesse contexto, o CFC (2007) afirma que, enquanto órgão representante da classe contábil no Brasil, ao regular o exame de suficiência como instrumento de licenciamento profissional, está defendendo o interesse público, pois cumpre o seu papel de selecionar bacharéis que tenham conhecimentos médios e, na sua concepção, garante à sociedade serviços com qualidade, informações contábeis seguras, mais precisas, e profissionais éticos, ou seja, que ofereçam, trabalhos mais qualitativos.

\subsection{Estudos relacionados}

A fim de embasar o presente estudo, realizou-se uma pesquisa bibliográfica objetivando identificar a ocorrência de publicações específicas sobre exames de licenciamento profissional. Entende-se que isso viabiliza conhecer o tratamento que outros pesquisadores têm dado ao assunto.

Foram consultados os estudos em bases de dados, como o portal de periódicos da Capes, SciELO, Science Direct e a plataforma EBSCOhost. A pesquisa também contou com acesso à trabalhos apresentados em congressos brasileiros sobre o exame de suficiência e a consulta em acervos de teses e dissertações de universidades. As consultas foram realizadas com as seguintes expressões: "professional licensing exams" AND "accounting AND "sufficiency exam" OR "exames de licenciamento profissional" AND "contabilidade" AND "exame de suficiência.

Iniciativas de estudos semelhantes têm sido comuns na literatura de licenciamento profissional. Com base na revisão bibliográfica realizada, alguns estudos nacionais e internacionais desenvolvidos foram encontrados. A Figura 1 apresenta os estudos mais diretamente relacionados ao objeto desta pesquisa.

\begin{tabular}{|c|c|c|}
\hline Autor & Título & Objetivos \\
\hline Peterson e Reider (2002) & $\begin{array}{l}\text { Percepções de testes baseados em } \\
\text { computador: um foco no exame CFM }\end{array}$ & $\begin{array}{l}\text { Analisar os testes computadorizados } \\
\text { como uma alternativa viável aos } \\
\text { exames de papel e lápis, relatando as } \\
\text { percepções de candidatos a Certified } \\
\text { in Financial Management - CFM }\end{array}$ \\
\hline Galvão (2016) & $\begin{array}{l}\text { Percepção dos Contadores sobre o exame de } \\
\text { suficiência do CFC }\end{array}$ & $\begin{array}{l}\text { Verificar a percepção dos } \\
\text { contadores quanto a realização do } \\
\text { exame de suficiência. }\end{array}$ \\
\hline Santos e Andrade (2016) & $\begin{array}{l}\text { Exame de suficiência sobre a perspectiva } \\
\text { dos profissionais da contabilidade que } \\
\text { tiveram artigos publicados em revistas } \\
\text { Qualis B3 }\end{array}$ & $\begin{array}{l}\text { Analisar a opinião dos autores que } \\
\text { publicaram artigos em revistas } \\
\text { nacionais, com Qualis B3 acerca do } \\
\text { exame de suficiência. }\end{array}$ \\
\hline $\begin{array}{l}\text { Miranda, Araújo e Miranda } \\
\text { (2017) }\end{array}$ & $\begin{array}{l}\text { O exame de suficiência em contabilidade: } \\
\text { uma avaliação sob a perspectiva dos } \\
\text { pesquisadores }\end{array}$ & $\begin{array}{l}\text { Identificar a percepção de docentes } \\
\text { e profissionais sobre o exame de } \\
\text { suficiência para profissão contábil, } \\
\text { bem como avaliar seu atual modelo. }\end{array}$ \\
\hline Morikawa (2018) & $\begin{array}{l}\text { Licenças ocupacionais e resultados do } \\
\text { mercado de trabalho no Japão }\end{array}$ & $\begin{array}{l}\text { Apresentar evidências empíricas } \\
\text { sobre a relação entre licenças } \\
\text { ocupacionais e resultados do } \\
\text { mercado de trabalho no Japão. }\end{array}$ \\
\hline $\begin{array}{l}\text { Souza, Bareto e Gomes } \\
\quad \text { Filho } \text { et al. (2019) }\end{array}$ & $\begin{array}{l}\text { Percepção docente sobre o exame de } \\
\text { suficiência contábil: um estudo em uma } \\
\text { instituição de ensino superior do município } \\
\text { de Icó, Ceará - Brasil }\end{array}$ & 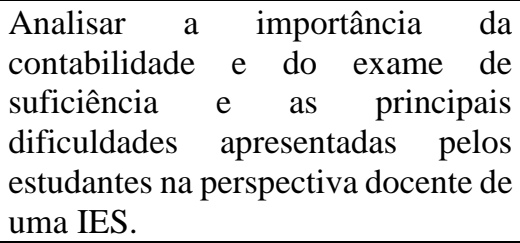 \\
\hline
\end{tabular}

Figura 1. Estudos nacionais relacionados

Fonte: Dados da Pesquisa (2019). 
A pesquisa de Peterson e Reider (2002) foi realizada com 200 candidatos que obtiveram êxito na realização do exame CFM (Certified in Financial Management) e 200 candidatos que apresentaram resultados não satisfatório. Os resultados foram positivos com o exame computadorizado, contudo, os autores afirmam que o teste é um mal necessário para quem busca certificação profissional.

O estudo de Galvão (2016), realizado com os contadores cadastrados nos Conselhos Regionais de Contabilidade das unidades federativas do Brasil, tem como principal resultado a confirmação da necessidade de melhor adequação da prova à realidade empresarial. Além disso o autor constatou que $89,55 \%$ são favoráveis a continuidade do exame.

Santos e Andrade (2016) concluíram que, em sua maior parte, os docentes não se adequaram em sala de aula com a volta do exame, considerando seus conteúdos atualizados em relação aos cobrados na prova, assim como não realizam preparação específica dos alunos para sua realização.

Já Miranda et al. (2017), em seus estudos, tiveram como público alvo os pesquisadores e profissionais que publicaram em congressos e periódicos da área contábil, cerca de 1185 respondentes, correspondendo a um retorno de $34,8 \%$ da base enviada. A pesquisa concluiu que, de forma geral, as questões aplicadas no exame foram consideradas medianas, porém um total de $70 \%$ dos docentes costuma utilizá-las, em maior ou menor grau, em suas atividades didáticas.

Para Morikawa (2018) a posse de credenciais ocupacionais particularmente licenças, tem associações positivas com a vinculação do mercado de trabalho e salário de indivíduos. Por outro lado, o sistema de licenciamento ocupacional pode afetar negativamente a eficiência do mercado por meio de rendas monopolistas.

Na concepção de Souza et al. (2019), através da pesquisa realizada com os docentes do curso de Ciências Contábeis de uma Instituição de Ensino Superior o exame de suficiência é necessário e contribui de maneira significativa na vida profissional, funcionando como um instrumento de filtragem, permitindo, assim, o estabelecimento de graduados que se preparam efetivamente enquanto alunos.

Diante do exposto, acredita-se que os estudos realizado por Peterson e Reider (2002), Santos e Andrade (2016), Galvão (2016), Miranda et al. (2017), Morikawa (2018) e, Souza et al. (2019), que abordaram os exames de licenciamento profissional, podem trazer contribuições complementares a presente pesquisa, tanto na construção do referencial teórico quanto na análise.

\section{METODOLOGIA}

Este estudo classifica-se como pesquisa exploratória-descritiva, uma vez que busca descrever as funções do exame de suficiência na percepção dos alunos do curso de graduação em Ciências Contábeis. Para Marconi e Lakatos (2010) pesquisas exploratório-descritivo são estudos que tem por objetivo descrever completamente determinado fenômeno.

Antes da aplicação, o instrumento de pesquisa foi submetido a um pré-teste realizado com pesquisadores sobre o estudo e que não integravam a população selecionada. Nessa fase foram avaliadas a abrangência e a compreensão das assertivas, considerando que o instrumento de pesquisa foi elaborado com base na literatura estabelecida no referencial teórico e validando o instrumento com adaptações efetuadas com base nas sugestões apontadas no pré-teste. As principais alterações decorrentes do pré-teste foram: (1) readequação dos itens que compuseram os blocos das assertivas; e (2) redefinição textual de algumas assertivas para melhor compreensão por parte do respondente.

As afirmativas eram respondidas em uma escala do tipo Likert de 5 pontos. O público alvo da pesquisa foi composto por alunos de graduação em Ciências Contábeis, de uma universidade pública, localizada no interior do Estado de Mato Grosso. A população de estudo era composta por 320 alunos. Contudo, recebeu-se como resposta o total de 188 questionários, aproximadamente $58,75 \%$ de retorno, conforme apresentado na Tabela 1. 
Tabela 1

Retorno do questionário por semestre

\begin{tabular}{c|c|c}
\hline Semestre & Frequência & Porcentagem \\
\hline $1^{\circ}$ Semestre & 36 & $19,1 \%$ \\
\hline $2^{\circ}$ Semestre & 22 & $11,7 \%$ \\
\hline $3^{\circ}$ Semestre & 29 & $15,4 \%$ \\
\hline $4^{\circ}$ Semestre & 29 & $15,4 \%$ \\
\hline $5^{\circ}$ Semestre & 24 & $12,8 \%$ \\
\hline $6^{\circ}$ Semestre & 10 & $5,4 \%$ \\
\hline $7^{\circ}$ Semestre & 19 & $10,1 \%$ \\
\hline $8^{\circ}$ Semestre & 19 & $10,1 \%$ \\
\hline Total & 188 & $100 \%$ \\
\hline
\end{tabular}

Fonte: Dados da pesquisa (2019).

A coleta de dados foi realizada por meio de pesquisa aplicado pessoalmente pelos pesquisadores na semana entre 23 e 27 de setembro de 2019. O instrumento de pesquisa foi dividido em duas partes e adaptado pelos autores com base na literatura encontrada e disposta no referencial teórico. Na primeira parte os discentes responderam às seguintes informações: a) gênero, b) idade e c) semestre que cursava. A segunda seção é constituída por afirmativas sobre o de exame de suficiência (ver Tabela 2).

Tabela 2

Síntese da construção do instrumento de pesquisa

\begin{tabular}{|c|c|c|}
\hline \multicolumn{3}{|c|}{$1^{\mathrm{a}}$ parte - Perfil dos participantes } \\
\hline \multirow[t]{3}{*}{ Perfil dos participantes } & Gênero & \\
\hline & Idade & \\
\hline & Semestre em que estava cursando & \\
\hline \multicolumn{3}{|c|}{$2^{\mathrm{a}}$ parte - Percepção dos alunos quanto ao Exame de Suficiência } \\
\hline \multirow{5}{*}{$\begin{array}{lr}\text { O Exame } & \text { de } \\
\text { suficiência e } & \text { a } \\
\text { profissão contábil } & \end{array}$} & $\begin{array}{l}\text { Sua aplicação é importante e necessária para a profissão } \\
\text { contábil. }\end{array}$ & Figueiredo (2017). \\
\hline & Valoriza a profissão contábil. & $\begin{array}{l}\text { Galvão (2016); Miranda et } \\
\text { al. (2017) }\end{array}$ \\
\hline & Eleva a qualidade da profissão. & $\begin{array}{l}\text { Galvão (2016); Miranda et } \\
\text { al. (2017) }\end{array}$ \\
\hline & $\begin{array}{l}\text { Contribui para que a profissão contábil acompanhe as } \\
\text { demandas do mercado globalizado. }\end{array}$ & $\begin{array}{l}\text { Galvão (2016); Miranda et } \\
\text { al. (2017) }\end{array}$ \\
\hline & Contribui para a evolução da profissão contábil. & Galvão (2016) \\
\hline \multirow{6}{*}{$\begin{array}{l}\text { O Exame de } \\
\text { suficiência e o } \\
\text { profissional de } \\
\text { contabilidade }\end{array}$} & $\begin{array}{l}\text { O Exame de suficiência é um instrumento importante na } \\
\text { formação dos profissionais de contabilidade. }\end{array}$ & Santos e Andrade (2016) \\
\hline & $\begin{array}{l}\text { A aprovação no Exame de Suficiência abre novas } \\
\text { oportunidades para o profissional de contabilidade. }\end{array}$ & Miranda et al. (2017) \\
\hline & $\begin{array}{l}\text { Assegura profissionais mais capacitados para prestarem } \\
\text { serviços de qualidade a sociedade }\end{array}$ & $\begin{array}{l}\text { Santos e Andrade (2016); } \\
\text { Souza et al. (2016) }\end{array}$ \\
\hline & $\begin{array}{l}\text { Garante profissionais com um nível mínimo de } \\
\text { conhecimento para o exercício da profissão. }\end{array}$ & $\begin{array}{l}\text { Galvão (2016); Santos e } \\
\text { Andrade (2016) }\end{array}$ \\
\hline & $\begin{array}{l}\text { Direciona a formação de profissionais para atender a área } \\
\text { pública. }\end{array}$ & Galvão (2016) \\
\hline & $\begin{array}{l}\text { Direciona a formação de profissionais para atender a área } \\
\text { privada. }\end{array}$ & Galvão (2016) \\
\hline \multirow{4}{*}{$\begin{array}{l}\text { O Exame de } \\
\text { Suficiência e o ensino } \\
\text { do curso de Ciências } \\
\text { Contábeis }\end{array}$} & $\begin{array}{l}\text { A aprovação ou não no Exame de Suficiência serve como } \\
\text { um indicador de desempenho e qualidade do profissional } \\
\text { e do curso. }\end{array}$ & $\begin{array}{l}\text { Galvão (2016); Miranda et } \\
\text { al. (2017); Santos e Andrade } \\
(2016)\end{array}$ \\
\hline & $\begin{array}{l}\text { O conteúdo apresentado em sala de aula é suficiente para } \\
\text { a aprovação no Exame de Suficiência. }\end{array}$ & Miranda et al. (2017) \\
\hline & $\begin{array}{l}\text { Os professores incluem questões do Exame de Suficiência } \\
\text { nas atividades acadêmicas. }\end{array}$ & Santos e Andrade (2016) \\
\hline & $\begin{array}{l}\text { O assunto Exame de Suficiência é discutido com } \\
\text { frequência dentro da sala de aula }\end{array}$ & Miranda et al. (2017) \\
\hline
\end{tabular}

Fonte: Adaptado pelos autores (2019). 
No processo de análise dos dados, utilizou-se o software SPSS® versão 22.0. As técnicas estatísticas aplicadas foram: estatística descritiva (média, mediana, frequência, máximo, mínimo e soma) e análise fatorial. A utilização da estatística descritiva é relevante para a pesquisa uma vez que possibilita "compreender o comportamento dos dados para identificar as tendências, variabilidades e valores atípicos" (Fávero, Belfiore, Silva \& Chan, 2009, p. 51). A finalidade da análise fatorial favorece "sintetizar as informações de um grande número de variáveis em número menor de variáveis ou fatores" (Hair Jr, Anderson, Tatham \& Black, 2009, p. 388).

Para a realização da análise fatorial, com o intuito de verificar o agrupamento de variáveis para formação de constructos, foram feitos os testes de Kaiser-Meyer-Olkin-KMO, que verifica a adequação da amostra, teste de esfericidade de Bartlett, para identificar a correlação entre as variáveis, e Alpha de Cronbach, para analisar a consistência interna dos fatores encontrados na análise fatorial. Na sequência são apresentadas as características da amostra pesquisada.

\section{ANÁLISE DOS RESULTADOS}

\subsection{Perfil dos respondentes}

Em relação ao público pesquisado, os alunos são do curso de graduação em Ciências Contábeis de uma universidade pública, localizada no interior do Estado de Mato Grosso, que oferece o curso de Ciências Contábeis na modalidade presencial. Os respondentes formam 188 discentes, sendo que, destes, 63,8\% (120) pertencem ao gênero feminino e 36,2\% (68) ao gênero masculino, conforme pode ser observado na Tabela 3.

Tabela 3

\section{Gênero}

\begin{tabular}{c|c|c}
\hline Gênero & Frequência & Porcentagem \\
\hline Feminino & 120 & $63,8 \%$ \\
\hline Masculino & 68 & $36,2 \%$ \\
\hline Total & $\mathbf{1 8 8}$ & $\mathbf{1 0 0 \%}$ \\
\hline
\end{tabular}

Fonte: dados da pesquisa (2019)

Em relação a idade, a grande maioria dos alunos concentra-se na faixa etária entre 20 e 25 anos, o que demonstra ser um curso formado por jovens, conforme pode ser constatado na Tabela4. Os resultados dessa análise correspondem ao trabalho de Nogueira, Nova e Carvalho (2012), os quais realizaram estudos investigando o bom professor na perspectiva da geração $\mathrm{Y}$, e constataram que há a presença de uma população considerável que é correspondente a essa faixa etária nos Cursos de Ciências Contábeis.

Tabela 4

Faixa etária

\begin{tabular}{c|c|c}
\hline Faixa etária & Frequência & Porcentagem \\
\hline Até 20 anos & 64 & 34 \\
\hline Entre 21 e 25 anos & 74 & 39,4 \\
\hline Entre 26 e 30 anos & 21 & 11,2 \\
\hline Entre 31 e 35 anos & 11 & 5,9 \\
\hline Acima de 35 anos & 18 & 9,5 \\
\hline Total & $\mathbf{1 8 8}$ & $\mathbf{1 0 0 \%}$ \\
\hline
\end{tabular}

Fonte: Dados da pesquisa (2019).

Quando questionados sobre o semestre que cursavam, os alunos matriculados do $1^{\circ}$ ao $4^{\circ}$ semestre somaram $61,60 \%$ dos respondentes, estando a maioria em uma etapa inicial do curso, conforme Tabela 5. 
Tabela 5

Semestre do curso

\begin{tabular}{c|c|c}
\hline Semestre & Frequência & Porcentagem \\
\hline $1^{\circ}$ Semestre & 36 & $19,1 \%$ \\
\hline $2^{\circ}$ Semestre & 22 & $11,7 \%$ \\
\hline $3^{\circ}$ Semestre & 29 & $15,4 \%$ \\
\hline $4^{\circ}$ Semestre & 29 & $15,4 \%$ \\
\hline $5^{\circ}$ Semestre & 24 & $12,8 \%$ \\
\hline $6^{\circ}$ Semestre & 10 & $5,4 \%$ \\
\hline $7^{\circ}$ Semestre & 19 & $10,1 \%$ \\
\hline $8^{\circ}$ Semestre & 19 & $10,1 \%$ \\
\hline Total & 188 & $100 \%$ \\
\hline
\end{tabular}

Fonte: Dados da pesquisa (2019).

Após breve apresentação do perfil dos respondentes, nos aspectos gênero, faixa etária e semestre do curso, serão apresentados os resultados decorrentes da análise dos dados sobre o exame de suficiência na percepção dos alunos pesquisados.

\subsection{Exame de suficiência: percepção dos alunos de Ciências Contábeis}

Iniciando a análise dos resultados da pesquisa, apuraram-se as médias de todos os itens do questionário, assim como seu desvio padrão e outras medidas da estatística descritiva, tais como: mediana, mínimo, máximo e soma conforme apresentado na Tabela 6.

Tabela 6

Percepções dos alunos de Ciências Contábeis quanto a realização do exame de suficiência

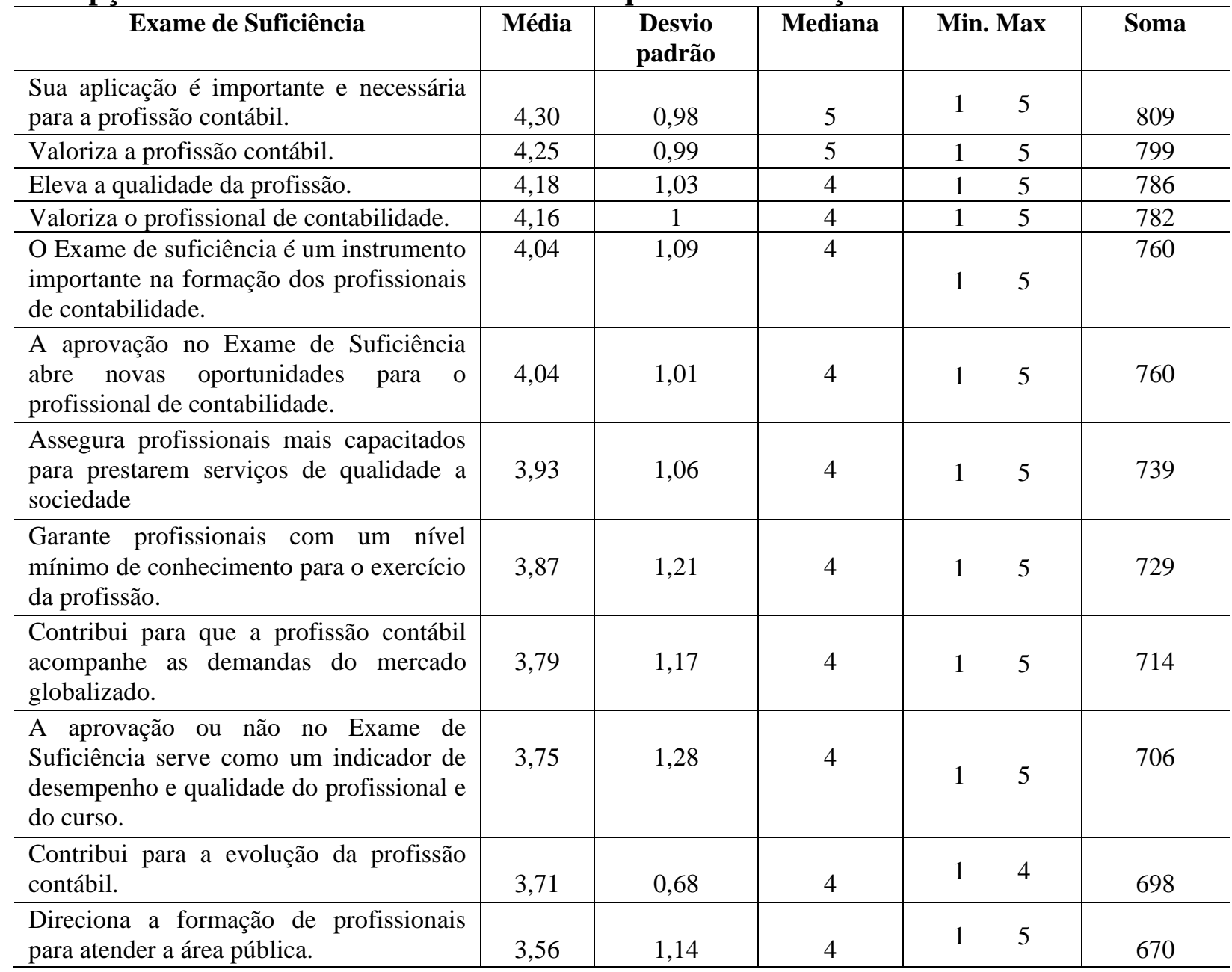




\begin{tabular}{|c|c|c|c|c|c|c|}
\hline $\begin{array}{l}\text { Direciona a formação de profissionais } \\
\text { para atender a área privada. }\end{array}$ & 3,50 & 1,17 & 4 & 1 & 5 & 658 \\
\hline $\begin{array}{l}\text { O conteúdo apresentado em sala de aula é } \\
\text { suficiente para a aprovação no Exame de } \\
\text { Suficiência. }\end{array}$ & 2,71 & 1,30 & 3 & 1 & 5 & 511 \\
\hline $\begin{array}{l}\text { Os professores incluem questões do } \\
\text { Exame de Suficiência nas atividades } \\
\text { acadêmicas. }\end{array}$ & 2,49 & 1,28 & 2 & 1 & 5 & 469 \\
\hline $\begin{array}{l}\mathrm{O} \text { assunto Exame de Suficiência é } \\
\text { discutido com frequência dentro da sala de } \\
\text { aula }\end{array}$ & 2,47 & 1,29 & 2 & 1 & 5 & 466 \\
\hline
\end{tabular}

Fonte: Dados da pesquisa (2019).

Conforme pode ser verificado na Tabela 6, a aplicação do exame de suficiência "é importante e necessária para a profissão contábil” $(4,30)$ aparece como a primeira característica mais relevante, seguida da "valorização". Ao analisar as características isoladamente, verifica-se que o exame de suficiência é importante e necessário para a classe contábil, pois prestigia a profissão, favorece a estima, dá mais credibilidade, eleva a qualidade dos serviços, valoriza o profissional de contabilidade, protege a sociedade de maus profissionais e, consequentemente, abre novas oportunidades aos futuros contadores. Nesse sentido, Pagliero (2011) explica que a entrada em muitas profissões depende de aprovações em exames de suficiência. Segundo o autor, os conselhos profissionais enfatizam que o único objetivo do exame de licenciamento é proteger o público. Para Bolt-Lee e Foster (2003) os profissionais têm que ter não somente conhecimentos sólidos de Contabilidade, mas também de outras vertentes, desenvolvendo o pensamento crítico como parte integrante da profissão.

A assertiva "valoriza o profissional contábil" (4,25) destaca-se como segunda característica relevante. Essa variável considerada pelos respondentes sinaliza que a realização do exame de suficiência proporciona valorização da classe contábil, corroborando com os resultados encontrados nos estudos de Galvão (2016) e Santos e Andrade (2016).

Para a variável "o conteúdo apresentado em sala de aula é suficiente para a aprovação no Exame de Suficiência" (2,71), constata-se que, dentre as assertivas, é a terceira média mais baixa. Infere-se desse dado que a forma como os alunos concebem os conteúdos apresentados pelos professores em sala de aula está relacionado, mesmo que indiretamente, com as dificuldades encontradas na realização do exame de suficiência, o que pode ocasionar em um resultado insatisfatório.

Chama-se a atenção para as variáveis "questões do exame de suficiência nas atividades acadêmicas" $(2,49)$ e "se o exame de suficiência é discutido com frequência em sala de aula" $(2,47)$. Estas variáveis não aparecem como características relevantes, obtendo as menores médias, apresentando discordância por parte dos alunos. Compreende-se, dessa maneira, que estas questões podem significar como um dos itens responsáveis pelo alto índices de reprovação no referido exame, pois esse resultado pode ser em decorrência da não percepção e falta de conexão dos alunos entre os conteúdos das atividades e os assuntos aplicados no exame de suficiência. Tal informação implica em observar que não há discussões e reflexões sobre a temática entre os alunos no espaço escolar, indicando que a preocupação com o exame tende a começar tardiamente para a maioria deles.

Esses achados são contrários aos encontrado por Miranda et al. (2017). Os autores constataram que as questões aplicadas no exame foram consideradas medianas, mas cerca de $70 \%$ dos docentes costumam utilizá-las relativamente em suas atividades didáticas. A divergência está na percepção dos docentes, pois estes afirmam que as questões do exame de suficiência compreendem suas atividades acadêmicas, entretanto, na percepção dos alunos questionados, na atual pesquisa o trabalho realizado em sala de aula como um todo não contemplam os temas abordados no exame de suficiência. 
Segundo Bugarim, Rodrigues, Pinho e Machado (2014), apesar das expectativas quanto aplicação, o que se observou nos resultados apresentados foi um decréscimo significativo nos níveis de aprovação no exame do CFC. Ainda, de acordo com a autora, os ensejos de que a exigência do exame de suficiência impulsionasse às instituições de ensino em vistas da melhoria na qualidade de seus cursos, não se realizaram.

\subsubsection{Análise Fatorial}

Com objetivo de verificar a possibilidade de condensar as informações da escala de mensuração utilizou da técnica de análise fatorial. No que concerne a adequação da amostra, esta foi medida por meio do teste de Kaiser-Meyer-Olkin (KMO), sendo aceitos valores acima de 0,50 (Maroco, 2003). Associado a isto, fez-se o teste de esfericidade de Bartlett, pois este é indicado para verificar a correlação entre as variáveis da escala. Esse teste é estatisticamente significante quando for menor que 0,05 , visto que indica se há correlações suficientes entre as variáveis (Hair Jr et al., 2009; Corrar, Paulo, Dias Filho \& Rodrigues, 2011).

Nesta pesquisa, verificou-se um KMO igual 0,934, sendo aceitável para prosseguir com a análise fatorial. Já o teste de esfericidade de Bartlett, foi bastante significante (Sig. =0,000) o que confirma a existência de correlação entre as variáveis, conforme Tabela 7.

Tabela 7

\section{Teste de KMO e Bartlett}

\begin{tabular}{l|l|l}
\hline Medida Kaiser-Meyer-Olkin de adequação de amostragem &, 934 \\
\cline { 1 - 2 } Teste de esfericidade de & Aprox. Qui-quadrado & 7670,307 \\
Bartlett & Df & 120 \\
& &, 000 \\
\hline
\end{tabular}

Fonte: Dados da pesquisa (2019).

Após os testes de KMO e Bartlett, executou-se a análise fatorial de todos os componentes, visando reduzir as variáveis em poucos constructos. Para a realização da análise fatorial, foi utilizada a rotação Varimax. A partir do resultado estatístico obtiveram-se os seguintes fatores, conforme Figura 2: (1) valorização profissional e (2) ambiente acadêmico.

\begin{tabular}{l|l}
\hline \multicolumn{1}{c|}{ Valorização profissional (0,992) } & \multicolumn{1}{c}{ Ambiente acadêmico (0,978) } \\
\hline $\begin{array}{l}\text { A aprovação ou não no Exame de Suficiência serve } \\
\text { como um indicador de desempenho e qualidade do } \\
\text { profissional e do curso. }\end{array}$ & $\begin{array}{l}\text { O assunto Exame de Suficiência é discutido com frequên } \\
\text { dentro da sala de aula. }\end{array}$ \\
\hline $\begin{array}{l}\text { Sua aplicação é importante e necessária para a } \\
\text { profissão contábil. }\end{array}$ & $\begin{array}{l}\text { Os professores incluem questões do Exame de Suficiência } \\
\text { nas atividades acadêmicas. }\end{array}$ \\
\hline Valoriza a profissão contábil & $\begin{array}{l}\text { O conteúdo apresentado em sala de aula é suficiente para a } \\
\text { aprovação no Exame de Suficiência. }\end{array}$ \\
\hline Eleva a qualidade da profissão. & $\begin{array}{l}\text { Direciona a formação de profissionais para atender a área } \\
\text { privada. }\end{array}$ \\
\hline Contribui para a evolução da profissão contábil. & $\begin{array}{l}\text { Direciona a formação de profissionais para atender a área } \\
\text { pública. }\end{array}$ \\
\hline $\begin{array}{l}\text { O Exame de suficiência é um instrumento importante } \\
\text { na formação dos profissionais de contabilidade. }\end{array}$ & \\
\hline Valoriza o profissional de contabilidade & \\
\hline $\begin{array}{l}\text { Garante profissionais com um nível mínimo de } \\
\text { conhecimento para o exercício da profissão. }\end{array}$ & \\
\hline $\begin{array}{l}\text { Assegura profissionais mais capacitados para } \\
\text { prestarem serviços de qualidade a sociedade. }\end{array}$ & \\
\hline $\begin{array}{l}\text { A aprovação no Exame de Suficiência abre novas } \\
\text { oportunidades para o profissional de contabilidade }\end{array}$ & \\
\hline
\end{tabular}

Figura 2. Fatores, seus componentes e o Alpha de Cronbach

Fonte: Dados da pesquisa (2019). 
Os fatores deram origem aos constructos apresentados Figura 2. Percebe-se que o exame de suficiência na percepção dos alunos de Ciências Contábeis é sintetizado em dois grupos: valorização profissional e ambiente acadêmico.

Para avaliar a confiabilidade interna dos constructos (fatores) foi realizada o teste do Alpha de Cronbach. Os resultados são apresentados na Tabela 9 dispostos entres parênteses a frente do nome dos fatores. Os resultados desse teste estatístico são aceitos quando forem superiores a 0,7. De acordo com Hair, Babin, Money e Samouel (2005) o alfa varia de 0 a 1, os pesquisadores geralmente consideram um alfa de 0,7 como mínimo, embora coeficiente mais baixos possam ser aceitáveis, dependendo dos objetivos da pesquisa.

A Tabela 8 refere-se ao resultado encontrado com a análise fatorial.

Tabela 8

Análise Fatorial Com Rotação Varimax Extraction Method: Principal Component Analysis Rotation Method: Varimax with Kaiser Normalization.

\begin{tabular}{l|c|c}
\hline \multicolumn{1}{c|}{ Item } & \multicolumn{2}{c}{ Componente } \\
\cline { 2 - 3 } & $\mathbf{1}$ & $\mathbf{2}$ \\
\hline Contribui para a evolução da profissão contábil. &, 958 &, 864 \\
\hline Sua aplicação é importante e necessária para a profissão contábil. &, 859 & \\
\hline Valoriza a profissão contábil &, 846 &, 807 \\
\hline Eleva a qualidade da profissão. &, 752 & \\
\hline Valoriza o profissional de contabilidade &, 743 & \\
\hline $\begin{array}{l}\text { O Exame de suficiência é um instrumento importante na formação dos profissionais de } \\
\text { contabilidade. }\end{array}$ &, 743 & \\
\hline Assegura profissionais mais capacitados para prestarem serviços de qualidade a sociedade. &, 704 & \\
\hline Garante profissionais com um nível mínimo de conhecimento para o exercício da profissão. & \\
\hline $\begin{array}{l}\text { A aprovação ou não no Exame de Suficiência serve como um indicador de desempenho e } \\
\text { qualidade do profissional e do curso. }\end{array}$ &, 702 & \\
\hline $\begin{array}{l}\text { A aprovação no Exame de Suficiência abre novas oportunidades para o profissional de } \\
\text { contabilidade }\end{array}$ &, 700 & \\
\hline Contribui para que a profissão contábil acompanhe as demandas do mercado globalizado. &, 930 \\
\hline Os professores incluem questões do Exame de Suficiência nas atividades acadêmicas. &, 926 \\
\hline O assunto Exame de Suficiência é discutido com frequência dentro da sala de aula. &, 885 \\
\hline $\begin{array}{l}\text { O conteúdo apresentado em sala de aula é suficiente para a aprovação no Exame de } \\
\text { Suficiência. }\end{array}$ & \\
\hline Direciona a formação de profissionais para atender a área privada. &, 699 \\
\hline Direciona a formação de profissionais para atender a área pública. &, 687 \\
\hline Fon & & \\
\hline
\end{tabular}

Fonte: Dados da pesquisa (2019).

Nesse sentido, verifica-se que os dois constructos, "valorização profissional" e "ambiente acadêmico", apresentam confiabilidade interna com resultados superiores a 0,7. Com base nos resultados da pesquisa, a percepção dos alunos de Ciências Contábeis quanto ao exame de suficiência esta sintetizado na Figura 3. 


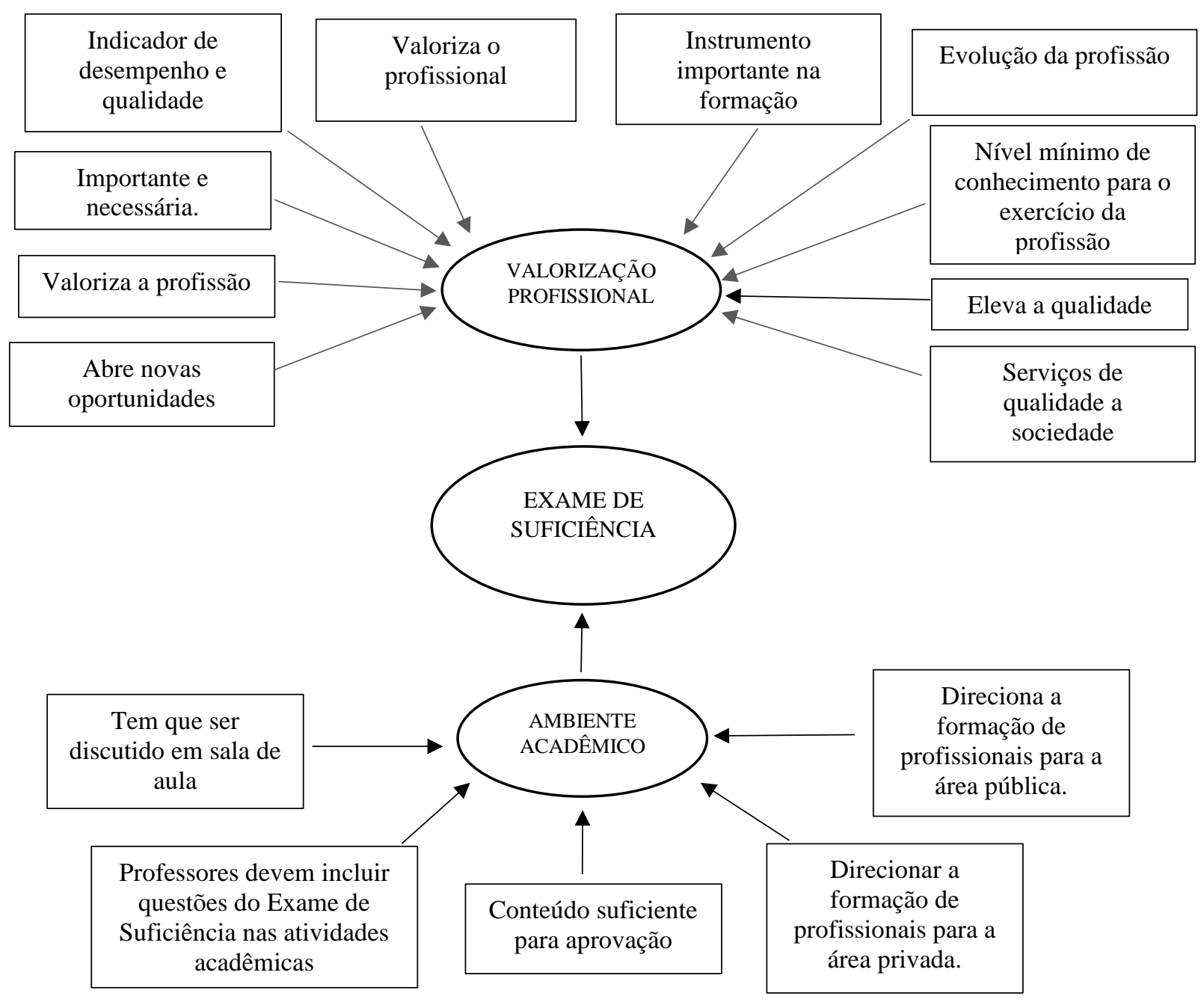

Figura 3. Constructos da percepção dos alunos de Ciências Contábeis quanto aplicação do exame de suficiência

Fonte: Dados da pesquisa (2019).

Diante do resultado estatístico encontrado a partir da realização na Análise Fatorial, é possível constatar 02 (dois) grupos: Valorização Profissional (1) e ambiente acadêmico (2) como fatores de percepção dos alunos para a realização do exame de suficiência. A Figura 1 possibilita compreender como esses fatores se interligam na realização do exame de suficiência.

Observa-se que a valorização profissional é o fator que explica em $88,15 \%$ a realização do exame de suficiência. Isso foi possível visualizar através da realização da análise fatorial que aproximou os fatores.

Infere-se desses resultados que, na percepção dos alunos de ciências contábeis, a profissão necessita da presença do exame de suficiência, uma vez que este garante à área Contábil o reconhecimento de relevância à sociedade e, por essa razão, atribuem alto valor à característica "valorização profissional".

O fator "Valorização Profissional" faz significar para a sociedade que os profissionais da área que irão atuar nas organizações, sejam elas públicas ou privadas, além de mais valorizados sejam mais capacitados, pois a presença de um instrumento avaliativo elava a qualidade profissional, abre novas oportunidades de emprego, visto que comprova que o sujeito contador possui os níveis mínimos de conhecimento para o exercício da profissão. Esses achados correspondem aos encontrados nos estudos de Galvão (2016), Santos e Andrade (2016) e Miranda et al. (2017); 
Outro fator que pode ser compreendido está em relação aos $6,49 \%$ da percepção dos alunos de ciências contábeis ligado ao "ambiente acadêmico". Observa-se que o exame de suficiência é um assunto que, apesar de ser considerado como relevante e significativo para a profissão contábil, percebe-se que este ainda é pouco discutido no ambiente acadêmico e que é preciso maior abordagem, não como forma de preparação específica, mas de incentivo à prática diária de aliar os estudos com a sua formação e atuação profissional. Considerando os dois fatores (valorização profissional e ambiente acadêmico) eles em conjunto explicam 94,65\% das funções do exame de suficiência, conforme pode ser constatado na Tabela 9.

Tabela 9

\section{Resultado da Análise Fatorial}

\begin{tabular}{l|c|c|c|c|c|c|c|c|c}
\hline \multirow{2}{*}{ Fatore } & \multicolumn{3}{|c|}{ Valores próprios iniciais } & \multicolumn{3}{c|}{$\begin{array}{c}\text { Somas de extração } \\
\text { de carregamento qo quadrado }\end{array}$} & \multicolumn{3}{c}{$\begin{array}{c}\text { Somas rotativas de } \\
\text { carregamento ao quadrado }\end{array}$} \\
\cline { 2 - 10 } & Total de cumulativo & $\begin{array}{c}\text { Total } \\
\text { variância }\end{array}$ & $\begin{array}{c}\% \text { de } \\
\text { variância }\end{array}$ & $\begin{array}{c}\% \\
\text { cumulativo }\end{array}$ & Total & $\begin{array}{c}\% \text { de } \\
\text { variância }\end{array}$ & $\begin{array}{c}\% \\
\text { cumulativo }\end{array}$ \\
\hline $\begin{array}{l}\text { valorização } \\
\text { profissional } \\
(0,992)\end{array}$ & 14,10 & 88,15 & 88,15 & 14,10 & 88,15 & 88,15 & 8,19 & 51,23 & 51,23 \\
\hline $\begin{array}{l}\text { ambiente } \\
\text { acadêmico } \\
(0,978)\end{array}$ & 1,04 & 6,49 & 94,65 & 1,04 & 6,49 & 94,65 & 6,94 & 43,42 & 94,65 \\
\hline
\end{tabular}

Fonte: Dados da pesquisa (2019).

A fim de explicar a ação de cada um desses fatores na percepção dos alunos de ciências contábeis quanto à realização do exame de suficiência, poderiam ser utilizadas outros tipos de análises estatística tais como regressão, equações estruturais, entre outras. Todavia, considerando as restrições da pesquisa em relação ao número de alunos participantes e a carência de bases teórica robusta de alguns fatores, não se consegue ir mais a frente nessa pesquisa. Deste modo, acendem singulares possibilidades de pesquisas para estudos futuros.

\section{CONSIDERAÇÕES FINAIS}

Esta pesquisa objetivou identificar as percepções dos alunos sobre a realização do exame de suficiência. Ao longo do referencial teórico buscou-se apresentar os resultados da literatura para a definição de exame de suficiência.

Como resultado da investigação, quando analisados individualmente a percepção mais valorizada pelos alunos como pertencentes ao exame de suficiência, obtiveram-se como resultado que o exame é importante e necessário para a profissão contábil, pois eleva a qualidade dos cursos e valoriza o profissional. Em contraponto a esses resultados e com médias mais baixas, segundo a percepção dos alunos, estão: que os professores incluem questões do exame de suficiência nas atividades acadêmicas e que o assunto exame de suficiência é discutido com frequência dentro da sala de aula.

Em complemento, utilizou-se a análise fatorial para criar constructos a partir da percepção dos alunos. Com o resultado obteve-se dois constructos, contribuindo com a literatura, sendo estes: valorização profissional e ambiente acadêmico. Dentre estes constructos, valorização profissional é o que apresenta maior peso, representado $88,15 \%$ do exame de suficiência, seguido do ambiente acadêmico com $6,49 \%$. Analisando em conjunto os resultados, infere-se que as percepções essenciais dos alunos em relação ao exame de suficiência estão ligadas à valorização profissional e indicador de desempenho acadêmico.

Considerando as limitações da pesquisa, por utilizar como amostra apenas um curso de graduação em Ciências Contábeis de uma universidade pública localizada no interior do Estado de Mato Grosso, alerta-se que os resultados dessa pesquisa não podem ser generalizados para outros cursos de graduação em Ciências Contábeis. O objetivo deste trabalho é entender e esclarecer que os achados da pesquisa podem contribuir para o entendimento do exame de 
suficiência da área de Ciências Contábeis na percepção dos alunos. Sugere-se que novas investigação busquem verificar o exame de suficiência na percepção dos docentes em outros cursos de graduação de Ciências Contábeis de outras regiões do Brasil.

\section{REFERÊNCIAS}

Akerlof, G. A. (1978). The market for "lemons": Quality uncertainty and the market mechanism. In Uncertainty in economics (pp. 235-251). Academic Press.

Barroso, D. V. (2018). Exame de Suficiência Profissional como indicador da Qualidade da Educação Contábil: Analisando as características das IES e seus índices de aprovação. Dissertação de mestrado, Universidade Federal da Bahia, Salvador, BA, Brasil.

Becker, G. (1986). The public interest hypothesis revisited: A new test of Peltzman's theory of regulation. Public choice, 49(3), 223-234.

Bolt-Lee, C., \& Foster, S. (2003). The core competency framework: A new element in the continuing call for accounting education change in the United States. Accounting Education, 12(1), 33-47.

Bugarim, M. C. C., Rodrigues, L. L., Pinho, J. C. C., \& Machado, D. Q. (2014). Análise histórica dos resultados do exame de suficiência do conselho federal de contabilidade. Revista Contabilidade e Controladoria, 6(1).

Conselho Federal de Contabilidade (1999). Resolução CFC n. 853. Institui o Exame de Suficiência como requisito para obtenção de Registro Profissional em CRC. Brasília: CFC.

Conselho Federal de Contabilidade (2007). Caderno analítico do exame de suficiência: histórico dos resultados. Brasília: CFC.

Conselho Federal de Contabilidade (2015). Resolução CFC n. 1486. Regulamenta o Exame de Suficiência como requisito para obtenção de Registro Profissional em Conselho Regional de Contabilidade (CRC). Brasília: CFC.

Corrar, L., Paulo, E., Dias Filho, J. M., \& Rodrigues, A. (2011). Análise multivariada para os cursos de administração, ciências contábeis e economia.

Cox, C., \& Foster, S. (1990). The costs and benefits of occupational regulation. Washington, DC: Bureau of Economics, Federal Trade Commission.

Fávero, L. P. L., Belfiore, P. P., Silva, F. L. D., \& Chan, B. L. (2009). Análise de dados: modelagem multivariada para tomada de decisões. Rio de Janeiro: Elsevier.

Figueiredo, A. E. S., Pederneiras, M. M. M., Saeger, M. M. D. M. T., Silva Filho, G. M. da, \& Nascimento, D. J. do (2017). Exame de suficiência profissional na perspectiva de graduandos do Curso de Ciências Contábeis: Um estudo em uma instituição pública de Ensino Superior. Revista de Contabilidade Dom Alberto, 6(11), 156-177.

Galvão, N. (2016). Percepção dos contadores sobre o exame de suficiência do CFC. Revista Catarinense da Ciência Contábil, 15(45), 49-62. 
Graddy, E. (1991). Toward a general theory of occupational regulation. Social science quarterly, 72(4), 676-695.

Grant, C. T., Ciccotello, C. S., \& Dickie, M. (2002). Barriers to professional entry: how effective is the 150-hour rule? Journal of Accounting and Public Policy, 21(1), 71-93.

Hair Jr, J. F., Anderson, R. E., Tatham, R. L., \& Black, W. C. (2009). Tradução: Adonai Schlup Sant 'Anna e Anselmo Chaves Neto. Análise Multivariada de Dados, 5.

Hair, J., Babin, B., Money, A., \& Samouel, P. (2005). Fundamentos de métodos de pesquisa em administração. Bookman Companhia Ed.

Lei $n^{\circ} 12.249$ (2010). [...] altera os Decretos-Leis n ${ }^{\circ}$ 9.295, de 27 de maio de 1946, 1040, e 21 de outubro de 1969 [...]. Brasilia, DF: Presidência da República.

Leland, H. E. (1979). Quacks, lemons, and licensing: A theory of minimum quality standards. Journal of political economy, 87(6), 1328-1346.

Madeira, G. J., Mendonça, K. F. C., \& Abreu, S. M. (2003). A disciplina teoria da contabilidade nos exames de suficiência e provão. Contabilidade Vista \& Revista, 14, 103-122.

Marconi, M. D. A., \& Lakatos, E. M. (2010). Fundamentos de Metodologia Cientifica (7a ed.). Rio de Janeiro: Editora Atlas.

Miranda, C. D. S., Araújo, A. M. P. D., \& Miranda, R. A. D. M. (2017). O exame de suficiência em contabilidade: uma avaliação sob a perspectiva dos pesquisadores. Revista Ambiente Contábil, 9 (2), 158-178.

Morikawa, M. (2018). Occupational licenses and labor market outcomes in Japan. Japan and the World Economy, 48, 45-56.

Maroco, J. (2003). Análise estatística: com utilização do SPSS.

Nogueira, D. R., Nova, S. P. D. C. C., \& Carvalho, R. C. O. (2012). O bom professor na perspectiva da geração Y: uma análise sob a percepção dos discentes de Ciências Contábeis. Enfoque: reflexão contábil, 31(3), 37-52.

Pagliero, M. (2011). What is the objective of professional licensing? Evidence from the US market for lawyers. International journal of industrial organization, 29(4), 473-483.

Peltzman, S. (1976). Toward a more general theory of regulation. The Journal of Law and Economics, 19(2), 211-240.

Peterson, B. K., \& Reider, B. P. (2002). Perceptions of computer-based testing: a focus on the CFM examination. Journal of Accounting Education, 20(4), 265-284.

Rabuske, E. (1995). Antropologia filosófica. Petrópolis: São Paulo: Vozes.

Santos, G. C., \& Andrade, S. A. (2016). Exame de Suficiência sobre a Perspectiva dos Profissionais da Contabilidade que Tiveram Artigos Publicados em Revistas com Qualis B3. RAGC, 4(15). 
Sprenger, K. B., Kronbauer, C. A., Silvestre, A. O., Azevedo, E. R., \& Alves, T. W. (2018). Fatores explicativos dos índices de aprovação no exame de suficiência contábil. ConTexto, 18(38).

Stigler, G. J. (1971). The theory of economic regulation. The Bell journal of economics and management science, 3-21.

Souza, C. N. P., Barreto, T. V., \& Gomes Filho, A. S. (2019). Percepção Docente sobre o Exame de Suficiência Contábil: Um Estudo em uma Instituição de Ensino Superior do Município de Icó, Ceará-Brasil. Id on Line Revista Multidisciplinar e de Psicologia, 13(43), 280-294.

Thornton, R. J., Timmons, E., \& De Antonio, D. (2017). Licensure or license? prospects for occupational deregulation. Labor Law Journal, 68(1), 46-578. 